\title{
A PASSAGEM DO TEMPO NA REALIDADE INTERIOR: INTUIÇÃO E DURAÇÃO NA FILOSOFIA DE HENRILOUIS BERGSON
}

\author{
Juliana Maria Martins ${ }^{1}$
}

\begin{abstract}
RESUMO: O artigo analisa a concepção bergsoniana da passagem do tempo em relação à realidade interior de cada indivíduo, conceituada como uma duração movida pela intuição. Por meio do método intuitivo do filósofo Henri-Louis Bergson, compreende-se o problema da espacialização do tempo lógico da física, que dispõe de um esquema espacial, cuja mensuração, por consequência, vai obscurecer as características do tempo real, que agrega continuidade, sucessões e criação.
\end{abstract}

Palavras-chave: Bergson; Espaço; Tempo; Duração; Intuição.

\section{THE PASSAGE OF TIME IN INNER REALITY: INTUITION AND DURATION IN HENRILOUIS BERGSON PHILOSOPHY}

\begin{abstract}
In this article, I analyze the Bergsonian concept of time in relation to each individual's personal reality, which is conceptualized as the duration moved by intuition. By using the intuitive method of the philosopher Henri-Louis Bergson, it is understood the spatialization issue of the logical time of physics, comprising a spatial scheme, whose mensuration will consequently obscure the real time characteristics, which aggregates continuity, successions and creation.
\end{abstract}

Keywords: Bergson; Space; Time; Duration; Intuition.

\section{INTRODUÇÃO}

O tempo percebido a partir da realidade interior dos indivíduos é o que HenriLouis Bergson chama de duração, uma sequência ininterrupta dos momentos diversos da vivência humana, que agrega sentimentos, emoções distintas e contínuas. É o “correr do tempo" único que existe em cada ser. O filósofo compreende também que a realidade dos indivíduos nem sempre é percebida de maneira simultânea.

\footnotetext{
${ }^{1}$ Mestre em Ciências Humanas, Sociedade, Cultura e Linguagem com Especialização em Arqueologia, História e Sociedade pela Universidade de Santo Amaro (UNISA). Possui Licenciatura em História pelo Centro Universitário da Estácio. Membro estudante no grupo de Pesquisa: Arte, Cultura e Imaginário e Estudos Interdisciplinaresem Educação, vinculados à UNISA. O grupo de pesquisa foi certificado pelo CNPQ em 2013 e filiado ao Centro de Recherche Inter disciplinairesurl' Imaginaire da Universidade de Grenoble, na França, em 2015. E-mail: egito811@ gmail.com.
} 
Esse é um problema ocasionado pelo tempo "físico e divisível", diferente do "tempo vivido". A duração do tempo uno está atrelada à consciência. A espacialização do tempo quantitativo opõe-se a esta possibilidade de perceber o tempo qualitativo. A compreensão da passagem do tempo, que corresponde à duração em cada individuo, foi "obscurecida" pela forma de se abstrair as coisas com base em um ritmo descontínuo da existência humana.

Para esclarecer o "conflito" proporcionado pelo pensamento lógico em relação à duração das coisas, é essencial compreender o processo de "evocação" da intuição. Deste modo, o referido artigo propõe-se analisar como o tempo uno é percebido na realidade interior dos indivíduos, partindo de dois aspectos específicos trazidos pela filosofia bergsoniana que envolve: o conceito de duração e intuição.

Nos estudos de Bergson, a duração do tempo é algo movida pela intuição. $\mathrm{Na}$ medida em que passamos a perceber as coisas de maneira intuitiva, deixamos de conceber a duração sob as ideias pré-determinadas pela sociedade. Este é um tipo de conhecimento oriundo da realidade distinta do conhecimento lógico das coisas, ou mesmo do conhecimento que as expressões do senso comum nos permitem saber.

Quer dizer que Bergson trata de esclarecer o problema das ciências que "coisificam" o homem por meio de abordagens que desconsideram a possibilidade de compreender os indivíduos em sua dimensão espiritual, inclusive, sob a sua capacidade intuitiva de perceber as coisas. Alcançar a duração do tempo humano de maneira qualitativa é o mesmo que olhar para o processo de duração que se realiza a partir das experiências vivenciadas, caracterizadas pela investigação das realidades individuais. Passemos, então, a tratar desses aspectos do pensamento filosófico de duração sob a crítica à concepção dominante do tempo e daquilo que seria o tempo real.

\section{TEMPO, INTUIÇÃO E DURAÇÃO}

O pensamento do filósofo Henri-Louis Bergson surgiu no momento em que o cientificismo predominava sob uma tendência positivista, entre o final do século XIX e a primeira metade do século $\mathrm{XX}$, “[...] quando eram legitimados, sobretudo, os conhecimentos construídos à semelhança das ciências ditas exatas: os dados deveriam 
ser empiricamente observados, medidos e inscritos em cadeias de causas e efeitos." (SAHM, 2011, p. 21).

\begin{abstract}
Assim eram tratados certos fenômenos da natureza. Era preciso, portanto que tais fenômenos se repetissem de forma absolutamente idêntica, para que se formulassem leis genéricas ou universais de funcionamento. Bergson, a exemplo de outros da sua época, observa a inadequação e mesmo a influência de tais métodos quando se trata de dar conta de fenômenos que envolvem a natureza humana e sua realidade interior (SAHM, 2011, p. 21).
\end{abstract}

O filósofo não foi o primeiro do seu tempo a observar as incongruências dos caminhos metodológicos e científicos; sobretudo, quando se tratava de dar conta de fenômenos que envolviam a realidade interior humana. Esta é a realidade que acaba trazendo territórios difíceis de serem analisados, na medida em que incorporam fenômenos distintos. Em Bergson e Proust, Estela Sahm (2011) compreende que, sob a realidade interna, "[...] dificilmente se verificam fenômenos idênticos, mas sim apenas análogos, guardando cada um deles suas especificidades; portanto, dificilmente poderíamos formular leis de funcionamento genéricas, baseadas em princípios de causas e efeitos." (SAHM, 2011, p. 21).

Contudo, o que Bergson define por "pensamento inteligente" não daria conta de organizar o fenômeno real da natureza humana. Essas questões podem ser observadas no capítulo "Introdução à Metafísica", tema desenvolvido por Bergson em $O$ pensamento e o movente, no qual o autor explana os diversos pontos a serem observados diante de um objeto de pesquisa.

\footnotetext{
Seja, por exemplo, o movimento de um objeto no espaço. Percebo-o diferentemente conforme o ponto de vista, móvel, do qual eu o observo. Exprimo-o diferentemente conforme o sistema de eixos ou de pontos de referência ao qual o remeto, isto é, conforme os símbolos pelos quais o traduzo. E chamo-o relativo por essa dupla razão: num caso como no outro, coloco-me fora do próprio objeto. Quando falo de movimento absoluto, é porque atribuo ao móvel um interior e como que estados de alma, é também porque simpatizo com os estados e neles me insiro por um esforço de imaginação. Então, conforme o objeto for móvel ou imóvel, conforme adotar um movimento ou um outro, não experimentarei a mesma coisa (BERGSON, 2006, p. 184).
} 
Diante desse conhecimento, o autor define que poderíamos nos concentrar no que de fato está em nós, mais independente do exterior e enraizado na essência interior, menos embutido na intelectualidade. Em vista disso,

Procuremos, no mais profundo de nós mesmos, o ponto no qual nos sentimos mais interiores a nossa própria vida. É na pura duração que mergulhamos então, uma duração na qual o passado, sempre em movimento, se avoluma incessantemente de um passado sempre novo (BERGSON, 2005, p. 217 218).

Quando se trata da filosofia do tempo bergsoniana, os conceitos não são tão fáceis de serem entendidos, por este motivo, iniciaremos este diálogo de maneira mais compreensível. A priori, vale lembrar que o filósofo opera com os conceitos que descaracterizam a maneira trivial de como as sociedades costumam pensar sobre o tempo. Desde que este passou a ser mensurado, o nosso entendimento em relação a ele desencadeia-se por forças externas, ou seja, o mundo externo e a maneira inteligente de pensar as coisas é o que predomina sobre o todo.

\begin{abstract}
[...] a inteligência, ao elaborar conceitos e ao trabalhar analiticamente, fragmentada, especializa e fixa a realidade que, nela mesma, é contínua mudanças qualitativa, puro torna-se. Mas, por outro lado, reconhece que essa forma de atividade intelectual, típica do "eu superficial", é aquela que possibilita a ciência e a própria sobrevivência do homem: está voltada, portanto, para o útil e o cômodo, permitindo não apenas a construção de símbolos e cálculos, como também a criação de máquinas e utensílios. A atividade do intelecto gerador de conceitos é de índole pragmática, fazendo com que o homem seja o "homo faber" que domina a natureza e a põe a seu serviço (BERGSON, 1979, p. X).
\end{abstract}

A inteligência atua no plano das abstrações, portanto, está fadada a "[...] permanecer no nível das relações entre os objetos, sendo incapaz de aprender o que cada objeto tem de essencial e de próprio." (BERGSON, 1979, p. X). Ora, a percepção do tempo atrela-se à realidade interiorizada. A duração do tempo não pode estar entranhada aos seguimentos mecanicistas a que nos habituamos, tendo como suporte, o tempo do relógio. A duração está submetida aos estados da consciência que atua sob o tempo de maneira contínua. Ademais, o problema está em dizer que os estados da consciência são limitados e separados entre si, ou que podem ser percebidos de maneira compartimentada pelos indivíduos. 
Quando afirmamos que as "coisas duram", isso significa que os estados da consciência não estão divididos entre passado, presente ou futuro, porque a consciência supera o tempo sem estas imposições artificiais da compreensão dos estados da consciência. Estas questões podem ser observadas quando estamos sob o domínio de emoções que não conseguimos controlar ou quando não compreendemos os motivos de tal sentimento. Neste caso, trata-se daquilo que a consciência não consegue obedecer.

Assim se inicia uma das questões mais importantes do pensamento de Bergson em relação à passagem do tempo, isto é, do ponto de vista da dimensão de vida que cada um tem. A duração seria, então, uma sequência contínua de movimento da vida, que se realiza em momentos distintos e ininterruptos "movidos" pelas emoções ou sentimentos.

Não seria possível refletir sobre a maneira como Bergson trata de compreender a duração do tempo em nós, sem ao menos salientar que os conceitos do autor foram desenvolvidos para compreendermos a questão do tempo como movimento contínuo. A filosofia de bergsoniana flui como uma "dança do ballet clássico", como aquele que executa os passos com cuidado e, executando-os, cada um no seu devido tempo para não confundir determinadas partes com outras, ou seja, esta é uma filosofia que "[...] vê na duração o próprio tecido de que a realidade é feita.” (BERGSON, 2005, p. 295).

Este é um tema que trata de alinhar duração como qualidades e não como quantidades. Isto propõe que as ideias difundidas em relação ao tempo não foram bem formuladas, visto que a tendência é a de mensurá-lo ou confundi-lo com o espaço. $\mathrm{Na}$ obra Bergsonismo, Gilles Deleuze (1999, p. 15) vai afirmar que "[...] medimos as misturas com uma unidade que é, ela própria, impura e já misturada."

Determinados eventos da vida cotidiana, sob o olhar do senso comum, ocorrem de maneira segmentada, como, por exemplo, aquelas atividades que agregam o caminhar no parque pela manhã ou uma corrida pela tarde. Quando os olhares são redirecionados para esses eventos, lá estão eles outra vez, um dia após o outro. Sejamos mais claros, a sociedade é constantemente "estimulada" a observar o tempo de maneira lógica e, por consequência disso, temos o costume de mensurar o tempo em horas, minutos e segundos, o que nos ajuda a organizar as coisas de maneira mais prática. Para Franklin Leopoldo (2009), 
Temos dificuldade em aceitar a realidade do tempo porque julgamos, a favor de nossa segurança prática e teórica, que o tempo é incompatível com a realidade. E assim, para representar o tempo sem a transitoriedade, emprestamos do espaço a permanência e a estabilidade, e forçamos o tempo a entrar nesse quadro. Assim concebemos a linha do tempo, as partes do tempo, a divisibilidade e mesmo a reversão: formamos desse modo o conceito do tempo que nada tem a ver com sua realidade. Mantemos uma relação com o tempo que é essencialmente mediada pela distância simbólica que o mecanismo de percepção e a estrutura intelectual proporcionam. $\mathrm{O}$ tempo, na vida comum, não é muito mais que uma palavra; e na ciência, assim como na filosofia, é um conceito (LEOPOLDO E SILVA, 2009, p. 1617).

Percebe-se claramente que este tempo "artificial" da vida cotidiana tende a "obscurecer" o outro tipo de tempo, aquele tempo que nos faz sentir as coisas acontecendo. Este fenômeno pode ser observado quando contemplamos o vôo de um pássaro, o crescimento das flores no jardim ou uma tempestade num dia de forte chuva. O dito popular "tudo possui o seu tempo" é uma maneira simples de perceber a passagem de um estado para o outro. As mudanças são inevitáveis, principalmente quando

\begin{abstract}
Constato de início que passo de um estado para outro. Tenho calor ou tenho frio, estou alegre ou estou triste, trabalho ou não faço nada, olho aquilo que me cerca ou penso em outra coisa. Sensações, sentimentos, representações, eis as modificações entre as quais a minha existência se reparte e que a colorem sucessivamente. Mudo, portanto, incessantemente. Mas isso é dizer muito pouco. A mudança é bem mais radical do que se poderia pensar a primeira vista (BERGSON, 2005, p. 1).
\end{abstract}

As mudanças ocorrem sem cessar nos indivíduos, mas a atenção para elas dá-se quando de fato lhe são significativas e é nesse momento que se tornam importantes ao ponto de atrair sua atenção. É possível notar que as mudanças imperceptíveis dos acontecimentos se tornam conscientes ao ocorrerem, por exemplo, de maneira drástica, como quando o combustível de um avião não é checado e, por consequência disto, ele cai no decorrer do trajeto. Diante desse acontecimento catastrófico, a sociedade questiona com indignação, "qual seria a causa deste acidente?" "Será que a culpa é do piloto?".

Isso ocorre "[...] precisamente porque fechamos os olhos às incessantes variações de cada estado psicológico, somos forçados, quando a variação se tornou tão 
considerável que se impõe à nossa atenção, a falar como se um novo estado se houvesse justaposto ao presente.” (BERGSON, 2005, p. 3).

Para entender a duração, necessitaríamos sair deste "entorpecimento" do tempo lógico para conhecer como o tempo é concebido a nossa maneira, pois estamos habituados a conviver com o tempo momentâneo, este que nos faz esquecer a duração em nós. Para tal perspectiva, Franklin Leopoldo (2009, p.17) considera que a

[...] intuição seria o meio de tentar atingir, tanto quanto possível, essa dimensão da realidade que para nós permanece oculta. "Intuição significa "pensar em duração" - não pensar a duração como "objeto", mas pensar em regime de duração, isto é, em contato com o tempo, a ele retornando para dele fazer uma experiência imediata (LEOPOLDO E SILVA, 2009, p. 1617).

É necessário encontrar meios de “[...] distinguir aqui nossa própria duração do tempo em geral. Em nossa duração, aquela que nossa consciência percebe, um intervalo dado só pode conter um número limitado de fenômenos conscientes." (BERGSON, 1999, p. 242).

O que chamamos comumente de "inspiração artística", por mais problemática que seja essa expressão, denota uma atitude desse tipo. Também a experimentamos quando somos tomados por profundas emoções e nos sentimos ameaçados de perder o controle inteligente que normalmente exercemos sobre nós mesmos. A relação mística, tão difícil de ser expressa e compreendida na articulação espacial da linguagem comum, também pode ser outro exemplo. São exatamente situações em que sentimos "faltar-nos o chão", isto é, o espaço em que nos movemos com segurança, previsão e estabilidade. É porque nesses casos estamos no tempo, isto é, na contingência, na imprevisibilidade, na indeterminação - lá onde poderíamos experimentar a liberdade de criar-nos a nós mesmos, como o artista cria uma obra quando se despoja de uma visão de mundo articulada e consolidada (LEOPOLDO E SILVA, 2009, p. 17).

Contudo, como introduzir a filosofia no âmbito do convívio humano cuja visão das coisas ainda se apresentam frente a esses conhecimentos sem sensibilidade às mudanças? Na obra A evolução criadora, Bergson vai explicar que a incorporação da filosofia no âmbito humano se dá "[...] ali onde há apenas um suave declive, cremos perceber, ao seguirmos a linha quebrada de nossos atos de atenção, os degraus de uma escada." (BERGSON, 2005, p. 3). Limitar-se apenas ao pensamento inteligente é o mesmo que estarmos privando-nos do desenvolvimento do conhecimento intuitivo. 
As sociedades estão "mergulhadas" na organização do tempo em relação à vida cotidiana; digamos, simplesmente, que a vida é mais do que cálculos numéricos e a duração em nós é impossível de ser medida. É justamente sobre isso que este texto procura dialogar, propõe-se que as coisas duram e que devemos senti-las para que possamos retomar o tempo em nós. Existem algumas inadequações em relação ao tempo que foram observadas e analisadas por Bergson, principalmente quando as análises buscam compreender os fenômenos que circundam a realidade da natureza humana.

O pensamento científico é de suma significância; entretanto, possui os seus limites, acredita-se que as observações científicas são válidas para os fenômenos de natureza físico-químicos das quais as ciências foram incumbidas de resolver. "Sem dúvida, a analise irá descobrir, nos processos de criação orgânica, um número crescente de fenômenos físico-químicos. E a isso se limitarão os químicos e físicos. Mas não se segue daí que a química e a física devam nos fornecer a chave da vida." (BERGSON, 2005, p. 34).

Quanto maior for o esforço em pensar sob o conceito de duração, mas estaremos olhando para dentro de nós. A duração é a essência do homem, conviver sem ela é o mesmo que interromper uma música quando ainda está em sua metade e, por consequência disso, deixarmos de compreender a sua essência: o que de fato o músico quis transmitir. "O universo dura. Quanto mais aprofundarmos a natureza do tempo, melhor compreendemos que duração significa invenção, criação de formas, elaboração continuada do absolutamente novo.” (BERGSON, 2005, p. 12).

Ecléa Bosi em Memória e Sociedade, Lembranças e Velhos aponta que os estudos de Henri Bergson em relação ao tempo entraram para a história do pensamento filosófico sob dois principais conceitos, um deles foi o "élan vital" (BOSI, 1994, p. 43), que corresponde a uma espécie de "impulso criativo" da evolução. O segundo conceito é o de "duração" que foi associado ao "tempo vivido" pelos indivíduos. Ambos os conceitos facilitam o pensamento crítico no que diz respeito ao espírito e à matéria, e como estes atuam na percepção estabelecedora da realidade humana.

Foram esses os temas que sofreram releitura significativa na filosofia bergsoniana, ao se buscar confrontar o conceito de tempo difundido pela lógica da física quantitativa. Na concepção do autor, os conceitos fundamentados pela lógica da ciência, 
ou pelo que ele chama de "inteligência" caminharam na contramão do que há de mais importante, as experiências vividas pelos indivíduos.

No Ensaio sobre os dados imediatos da consciência, enfatizou que "[...] contamos os movimentos sucessivos da duração e que, pelas suas relações com o número, o tempo nos sugere, em primeiro lugar, como uma grandeza mensurável, completamente análogo ao espaço, mas impõe-se então uma importante distinção." (BERGSON, s.d, p. 75).

Ao referir-se ao tempo e ao espaço, Bergson acredita ser compreensível que os indivíduos enxerguem ambos de maneira unificada; no entanto, é válido pôr em evidência que as concepções do filósofo vão desconsiderar a concepção do tempo elaborada por Einstein, enfatizando que o físico confunde os dois tipos de multiplicidade, impulsionando confusões entre o tempo e o espaço (DELEUZE, 1999, p. 67).

A justificativa de Bergson ao tratar o tempo de maneira qualitativa e não quantitativa, tem a ver com o tempo percebido a nossa maneira, por isso, não pode ser "medido". O tempo transita entre passado, presente e futuro, até parece não existir; no entanto, é possível percebê-lo como já foi enfatizado no início deste texto.

Relembramos que a percepção ocorre de maneira distinta a todos. Este pensamento sugere que o tempo não pode ser "medido", em razão de ele ser um processo sucessivo de continuidade e mudanças oriundas da consciência. Frederic Worms em seu artigo "A concepção bergsoniana do tempo" discorre "[...] que Bergson apresenta como decorrência, não da "questão" do tempo, mas da simples constatação da passagem do tempo [...]” (WORMS, 2004, p. 129).

Os estudos inerentes ao tempo estão “[...] nas fórmulas da mecânica, nos cálculos do astrônomo e até do físico, sob a forma de quantidade. Mede-se a velocidade de um movimento, o que implica também o tempo de uma grandeza" (BERGSON, s.d., p. 77). Transformar o tempo em quantidades numéricas, em cálculos, torna-se conflituoso no âmbito da esfera da nossa consciência, dá-nos a impressão de que o "nosso tempo" não é o tempo uno das qualidades, mas sim o tempo das quantidades.

O tempo em nós, por sua vez, vai desencadear mudanças, por isso é razoável pensar nele como algo impossível de aceitar uma medida comum. O tempo "livre" de intervenções psicológicas não representaria a nossa realidade, a duração do tempo 
implica, ativamente, um ato da consciência desenvolvida pelos seres humanos. O tempo não é passageiro, ele é a própria condição da passagem. Para Bergson, a partir da leitura de Frederic Worms:

[...] a duração não existe portanto senão "para" uma consciência, não é no sentido de que ela apareceria "a" uma consciência que seria a sua espectadora, mas na medida em que existiria, ela própria, como consciência, esta última sendo mesmo, por seu ato ou atividade própria, sua condição efetiva de possibilidade (WORMS, 2004, p. 133).

É com resistência que Bergson acentua que o problema do tempo está na sua mensuração e espacialização. Porém, não é prioridade deste texto debater a natureza e o alcance do espaço em sua totalidade, uma vez que seria um empreendimento de largo fôlego. Propõe-se apenas demonstrar que a natureza do espaço não se compara às características do tempo. A duração, tal qual podemos compreender, consiste em simultaneidade do tempo, muito diferente do espaço que Bergson (s.d., p. 69) considera como “[...] uma realidade sem qualidade.".

\footnotetext{
O que se torna necessário é afirmar que conhecemos duas realidades de ordem diferente, uma heterogênea, a das qualidades sensíveis, a outra homogênea, que é o espaço. Esta última, claramente concebida pela inteligência humana, permite-nos até efetuar distinções nítidas, contar, abstrair, e talvez também falar (BERGSON, s.d., p. 71).
}

Nesse caso, a representação de um espaço homogêneo demanda ser ocupado pelos objetos materiais, isto é pensar o espaço como um meio no qual os objetos se justapõem. "A representação de um espaço homogêneo deve-se a um esforço da inteligência. A representação, e não a percepção.” (PINTO, 1998, p. 147). No que concerne às observações do filósofo Immanuel Kant (2001), em Crítica da Razão Pura, o espaço está ligado à sua realidade empírica, isso significa que "[...] as coisas apenas se podem dar como extensas (realidade empírica do espaço). No entanto, se abstrairmos das condições da experiência, o espaço já não é nada.” (KANT, 2001, p. 13).

Quando se propõe que o espaço representa o meio pelo qual as pessoas possuem contato com o mundo externo, que é caracterizado pelos estímulos reais da nossa percepção, cabe então lançar uma pergunta: qual seria a realidade que o espaço agrega, inclusive, os seus aspectos? "Representamos os objetos como estando fora de nós e 
postos no espaço mediante a propriedade de nosso espírito que é o sentido externo." (KANT, 2009, p. 33).

No livro Matéria e Memória, Bergson (1999) procura definir que o espaço é homogêneo, e nele se insere a matéria, as qualidades sensíveis e os números. Immanuel Kant (2009) aponta que a “[...] geometria é uma ciência que delimita sinteticamente as propriedades do espaço e, por conseguinte, a priori." (KANT, 2009, p.34).

Entretanto, não devemos compreender que o espaço é algo ligado à matéria no sentido físico, porque, para ambos os filósofos, o espaço é uma construção do espírito. "O espaço "resulta" de um ato do espírito, de uma concepção da inteligência; é a própria forma desta, e condição de apreensão do mundo do sensível, tal qual o espaço kantiano." (PINTO, 1998, p. 135).

O tema da "espacialização do tempo" presente no diálogo de Bergson esclarece que a ciência detém a tendência de desapropriação da duração do tempo. Além disto, quando analisamos o tempo atrelado à percepção, este se alcança através do esforço intuitivo. Em suma, nota-se como o pensamento de Bergson propõe que a conquista do tempo parece ter agregado características daquilo que é concebido como passageiro na vida cotidiana. Apesar disso, foi possível compreender que o tempo é aquilo que dura, e o processo de duração ocorre de maneira contínua quando compreendido pelo ponto de vista da existência e da vivência humana.

\section{CONSIDERAÇÕES FINAIS}

Diante do exposto no texto, é possível observar que Bergson compreende o tempo dos físicos como uma espécie de linha estática, que se ocupa apenas em medir a duração das coisas de maneira prática e objetiva. Como podemos observar no texto, o problema do tempo está na sua “espacialização".

Quando Kat propõe observa o espaço como um meio pelo qual os indivíduos se conectam com o mundo externo, o autor faz uma associação entre a ideia de números e objetos materiais externos a nós, dando a entender que estes podem ser contabilizados, pensados separadamente e de maneira simultânea. Não é à toa que o filósofo enfatiza que as ciências geométricas procura delimitar, de maneira resumida, as particularidades do espaço. 
Seguindo essa lógica, quando se trata de sucessões múltiplas dos eventos cotidianos, só podemos contabilizá-los mediante as figurações simbólicas, na qual requer a necessidade do espaço. É comum pensar no tempo como algo homogêneo no qual podemos alinhar os fatos. Como bem enfatiza o autor Franklin Leopoldo, os indivíduos possuem dificuldades em agregar a verdadeira realidade do tempo, porque julgam ser de natureza incompatível com a realidade humana. Dessa maneira, procuram representar o tempo sem toda a sua transitoriedade, isso os faz procurar no espaço a permanência e estabilidade, colocando o tempo nessa condição de espacializado.

O conceito de Bergson sobre a duração do tempo e sua relação com a intuição contribuíram para a análise dos eventos oriundos da vivência humana. Compreende-se que a duração, que se realiza por intermédio da intuição, é um processo compreendido como um momento íntimo que cada ser humano vive em si. Assim, quanto mais tomamos consciência do nosso progresso em relação à duração, mais compreendemos que a duração é desencadeada por uma apreensão mais direta que o ser humano pode ter de si mesmo.

Quer se queira, quer não, quando se trata do tempo, não seria possível compreendê-lo sem esclarecer a problemática que o cerca, o que Bergson tratou como uma espécie de obscurecimento da realidade íntima da natureza humana. De fato, o tempo do relógio manifesta-se como passageiro, contudo, é exatamente este pensamento que dispersa a compreensão real do tempo que dura.

\section{BIBLIOGRAFIAS}

BERGSON, H. Cartas, conferências e outros escritos. Seleção de textos de Franklin Leopoldo e Silva. São Paulo: Abril Cultural, (Os pensadores), 1979

BERGSON, H. Ensaio sobre os dados imediatos da consciência. [1889] Tradução de João da Silva Gama. Lisboa: Edições 70, [S. d.].

BERGSON, Henri. A evolução criadora. Tradução Bento Prado Neto. São Paulo: Martins Fontes, (Coleção Tópicos), 2005.

BERGSON, Henri. Introdução à metafísica. In: O pensamento e o movente: ensaios e conferências. Tradução de Bento Prado Neto. São Paulo: Martins Fontes, p. 183-234, 2006. 
BERGSON, Henri. Matéria e memória: ensaio sobre a relação do corpo com o espírito. Tradução Paulo Neves. 2a (ed.). São Paulo: Martins Fontes, 1999.

BOSI, Ecléa. Memória e sociedade: Lembranças dos velhos. São Paulo: Companhia das Letras, 1994.

DELEUZE, G. Bergsonismo. Trad. de Luiz B. L. Orlandi. São Paulo: Ed. 34, (Coleção TRANS), 1999.

KANT, Immanuel. Crítica da Razão Pura. Trad. Lucimar A. Coghi Anselmi, Fulvio Lubisco. São Paulo: Martin Claret, (Coleção a obra-prima de cada autor; 3), 2009.

KANT, Immanuel. Crítica da Razão Pura. Trad. Manuela Pinto dos Santos e Alexandre Fradique Morujão. 5. ed. Lisboa, Fundação Calouste Gulbenkian, 2001a. Disponível em: <http://www.verlaine.pro.br/estetica/critica_da_razao_pura.pdf >. Acesso em: 24 de jul. 2018.

LEOPOLDO E SILVA, F. Tempo: experiência e pensamento. REVISTA USP, São Paulo, n.81, p. 6-17, março/maio 2009.

MARATO, Débora. O tempo e seus momentos interiores: heterogeneidade quantitativa e diferença interiorizada como marcas da duração bergsoniana. Analítica, volume 9, número 2, 2005. Disponível em: <file:///D:/Users/User/Downloads/509-979-1-SM\%20(1).pdf〉. Acesso em: 25 de jun 2018.

PINTO, Débora Cristina Morato. Espaço, Extensão e Número; Suas Relações e seu Significado na Filosofia Bergsoniana. Discurso, (29), 1998, p.133-174. Disponível em:

<http://filosofia.fflch.usp.br/sites/filosofia.fflch.usp.br/files/publicacoes/Discurso/Artigo s/D29/D29_Espaco_Extensao_e_Numero.PDF>. Acesso em: 02 de ago 2018.

SAHM, Estela. Bergson e Proust: sobre a representação da passagem do tempo. São Paulo: Iluminuras, 2011.

WORMS, F. A concepção bergsoniana do tempo. In: Dois pontos. Revista do Departamento de Filosofia da Universidade Federal do Paraná e da Universidade Federal de São Carlos, vol. 1, nº 1, 2004, pp. 129-149. 